\title{
Material models of cyclic plasticity with extended isotropic hardening: a review
}

\author{
Nobutada OHNO* \\ *Department of Mechanical Science and Engineering, Nagoya University \\ Furo-cho, Chikusa-ku, Nagoya 464-8603, Japan \\ E-mail: ohno@mech.nagoya-u.ac.jp
}

Received 30 September 2014

\begin{abstract}
This paper reviews the material models of cyclic plasticity in which memory surfaces are used to extend isotropic hardening. Focus is given to strain-range-dependent cyclic hardening and workhardening stagnation; the former is noticeable even at small strains, while the latter is evident at large strains and is thus considered one of the factors of accurate springback analysis. Because strain-range-dependent cyclic hardening and workhardening stagnation cannot be properly simulated by taking accumulated plastic strain as a measure of isotropic hardening, material models of cyclic plasticity have been proposed using memory surfaces to extend isotropic hardening. Material models developed in this way are reviewed, along with experimental observations.
\end{abstract}

Key words : Material model, Cyclic plasticity, Extended isotropic hardening, Cyclic hardening, Workhardening stagnation, Memory surface

\section{Introduction}

Metallic materials subjected to cyclic plastic loading may exhibit cyclic hardening/softening, the Bauschinger effect, ratcheting, and cyclic stress relaxation. These are the main phenomena dealt with in the material modeling of cyclic plasticity. In the phenomenological modeling of cyclic plasticity, it is conventionally assumed that workhardening consists of isotropic hardening/softening and kinematic hardening, which are, respectively, identified as the expansion/contraction and translation of yield surfaces. Isotropic hardening/softening is considered to be responsible for cyclic hardening/softening, whereas kinematic hardening is regarded as relating to the Bauschinger effect, ratcheting, and cyclic stress relaxation (e.g., Lemaitre and Chaboche, 1990).

Isotropic hardening is usually represented as a function of accumulated plastic strain, which was postulated by Odqvist (1933) as one of the pioneering contributions to plasticity (Bruhns, 2014a, 2014b). This measure of isotropic hardening can be appropriate under monotonic loading, but has been revealed to be inappropriate for simulating strain-range-dependent cyclic hardening and workhardening stagnation that may significantly occur under cyclic loading. Strain-range-dependent cyclic hardening and workhardening stagnation were first reported by Chaboche et al. (1979) and Hasegawa et al. (1975), respectively. The former is noticeable even at small strains, while the latter is conspicuous at large strains. To simulate these cyclic plastic phenomena, memory surfaces have been considered in either the plastic strain or the stress space to extend isotropic hardening, as reviewed in this paper.

Several review papers have been published on the phenomenological material modeling of cyclic plasticity. The cyclic plasticity/viscoplasticity model developed at ONERA, called Chaboche's model, has been reviewed, along with statements made for many other material models (Chaboche, 1986, 1989, 2008). The literature on cyclic plasticity was reviewed with respect to four main topics that gained attention especially in the 1970s and 1980s (Ohno, 1990). Developments in material modeling for ratcheting were highlighted in the review papers of Ohno (1997) and Kang (2008). In these review papers, however, the material modeling of workhardening stagnation was scarcely described, although workhardening stagnation is one of the notable factors in accurately predicting springback in sheet metal forming (Yoshida and Uemori, 2003; Ghaei et al., 2010; Yoshida, 2010). 
This paper reviews the material models of cyclic plasticity in which memory surfaces are used to extend isotropic hardening. This paper focuses on strain-range-dependent cyclic hardening and workhardening stagnation and is structured as follows. Section 2 describes classical measures of isotropic hardening as a base to start the present review. Sections 3 and 4 review the material models developed for strain-range-dependent cyclic hardening and workhardening stagnation, respectively. These sections also describe experimental observations. Applications to springback analysis are briefly reviewed in Section 4.4 in the context of this paper. A summary is given in Section 5 . It is noted that the present paper is not intended to review the material models of kinematic hardening because such models have already been reviewed by Chaboche (1986, 1989, 2008), Ohno (1990, 1997), and Kang (2008).

In this paper, direct notations are used for vectors and tensors, and inner products between them are indicated by middle dots or colons (e.g., $\mathbf{u} \cdot \mathbf{v}=u_{i} v_{i}, \quad \sigma: \varepsilon=\sigma_{i j} \varepsilon_{i j}$ ). A superposed dot denotes differentiation with respect to a time-like loading parameter, and \|\| signifies the Euclidian norm of second rank tensors (e.g., $\|\sigma\|^{2}=\sigma_{i j} \sigma_{i j}$ ).

\section{Classical measures of isotropic hardening}

It is conventionally assumed that workhardening consists of isotropic hardening/softening and kinematic hardening, which are, respectively, regarded as the expansion/contraction and translation of yield surfaces in rate-independent plasticity. The following yield function is thus usually considered for initially isotropic metallic materials (e.g., Lemaitre and Chaboche, 1990):

$$
f=\frac{3}{2}\left\|\sigma^{\prime}-\alpha^{\prime}\right\|^{2}-r^{2}
$$

where $\sigma^{\prime}$ and $\alpha^{\prime}$ denote the deviatoric parts of stress $\sigma$ and back stress $\alpha$, respectively, and $r$ indicates the radius of the yield surface $f=0$.

Schmidt (1932) and Odqvist (1933) proposed that plastic straining affects $r$ to induce workhardening through total plastic work $w_{\mathrm{p}}$ and accumulated plastic strain $p$, respectively (Bruhns, 2014a, 2014b):

$$
\begin{aligned}
& r=r\left(w_{\mathrm{p}}\right), \quad \dot{w}_{\mathrm{p}}=\sigma: \dot{\varepsilon}_{\mathrm{p}}, \\
& r=r(p), \quad \dot{p}=\sqrt{\frac{2}{3}}\left\|\dot{\varepsilon}_{\mathrm{p}}\right\|,
\end{aligned}
$$

where $\varepsilon_{\mathrm{p}}$ indicates plastic strain. The above two variables, $w_{\mathrm{p}}$ and $p$, are regarded as classical measures of isotropic hardening.

Currently, $p$ is more often considered as a measure of isotropic hardening than $w_{\mathrm{p}}$, as seen in commercial finite element software such as Abaqus and ANSYS. The following evolution equation of $r$ is frequently assumed to express the saturation of cyclic hardening (e.g., Lemaitre and Chaboche, 1990):

$$
\dot{r}=h_{r}\left(r_{\text {sat }}-r\right) \dot{p}, \quad r_{0}=r(0),
$$

where $h_{r}, r_{\text {sat }}$ and $r_{0}$ are material parameters. Equation (4) states that $r$ monotonically evolves from $r_{0}$ to $r_{\text {sat }}$ with an increase in $p$ :

$$
r=r_{0}+\left(r_{\text {sat }}-r_{0}\right)\left[1-\exp \left(-h_{r} p\right)\right]
$$

Here, it is emphasized that the saturation value $r_{\text {sat }}$ has no dependence on the strain range of cyclic loading.

\section{Strain-range-dependent cyclic hardening}

\subsection{Experimental observations}

Chaboche et al. (1979) performed a uniaxial cyclic test of $316 \mathrm{~L}$ stainless steel in which the strain range $\Delta \varepsilon$ was stepwise changed after the saturation of cyclic hardening (Lemaitre and Chaboche, 1990). They thus observed additional cyclic hardening, leading to resaturation, after each increase in $\Delta \varepsilon$ (Fig. 1(a)). They also observed a little 
recovery of cyclic hardening after a stepwise decrease in $\Delta \varepsilon$ (Fig. 1(b)). These results suggest that greater cyclic hardening can occur under cyclic loading with a larger strain range. This feature of cyclic hardening, referred to as strain-range-dependent cyclic hardening, has been observed in cyclic tests of other metals such as 304 stainless steel, 1070 steel, and oxygen-free high-conductivity (OFHC) copper (Ohno 1982; Jiang and Kurath, 1997; Kang et al., 2003; Jiang and Zhang, 2008), as exemplified in Fig. 2. A transmission electron microscopy (TEM) observation of $316 \mathrm{~L}$ stainless steel was made to find that cyclic loading with larger strain amplitudes causes more uniformly distributed dislocation cell structures (Mayama et al., 2008).

\subsection{Plastic strain memory surface}

Equation (5) has accumulated plastic strain $p$ as a measure of isotropic hardening, and expresses the saturation of $r$ at $r_{\text {sat }}$. Equations (1) and (5), thus, predict $\Delta \sigma=\Delta \alpha+2 r_{\text {sat }}$ in the saturated state of cyclic hardening under uniaxial cyclic loading, where $\Delta \sigma$ and $\Delta \alpha$ signify the ranges of stress and back stress under uniaxial cyclic loading. Here, $r_{\text {sat }}$ is a constant. Hence, if Eq. (5) is used, the dependence of cyclic hardening on the strain range is not simulated except for that of kinematic hardening.

To solve the problem described above, Chaboche et al. (1979) introduced a memory surface $g=0$ in the plastic strain space (Lemaitre and Chaboche, 1990), where $g$ is defined as

$$
g=\frac{2}{3}\left\|\boldsymbol{\varepsilon}_{\mathrm{p}}-\mathbf{q}\right\|^{2}-\rho^{2}
$$

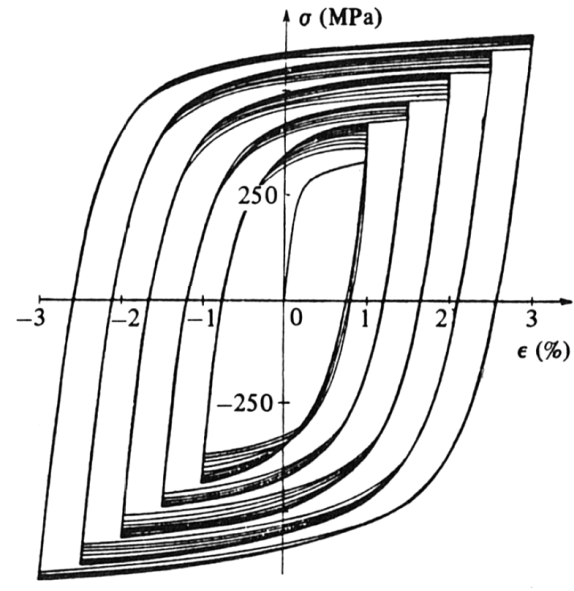

(a)

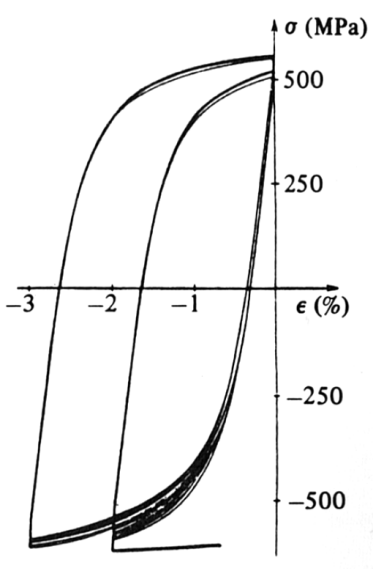

(b)

Fig. 1 Stress-strain hysteresis loops of 316L stainless steel subjected to cyclic loading with successive strain ranges of $2 \%, 3 \%, 4 \%, 5 \%, 6 \%, 2 \%$ and 3\%; (a) stepwise increasing process, and (b) stepwise decreasing process (Chaboche et al., 1979; Lemaitre and Chaboche, 1990).

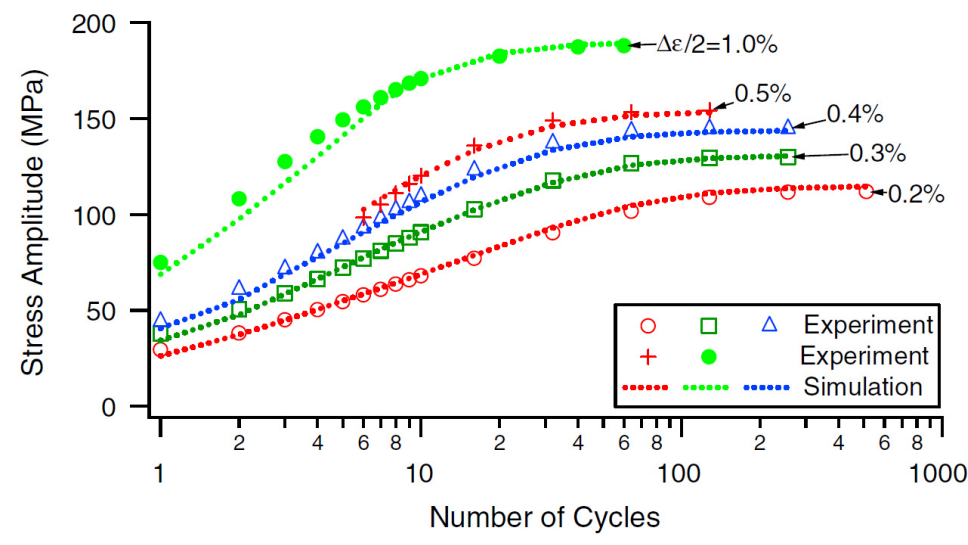

Fig. 2 Strain-range-dependent cyclic hardening of OFHC copper; experimental and simulated variations in stress amplitude under cyclic loading (Zhang and Jiang, 2008). 
Here, $\mathbf{q}$ and $\rho$ indicate the center and radius of the memory surface, and their evolution equations were prescribed for the surface $g=0$ to memorize the range of plastic strain under uniaxial cyclic loading:

$$
\dot{\mathbf{q}}=\frac{1}{2} H(g)\left(\dot{\boldsymbol{\varepsilon}}_{\mathrm{p}}: \mathbf{n}^{*}\right) \mathbf{n}^{*}, \quad \dot{\rho}=\frac{1}{2} H(g)\left(\mathbf{n}: \mathbf{n}^{*}\right) \dot{p},
$$

where $H$ is the Heaviside step function, and

$$
\mathbf{n}^{*}=\frac{\varepsilon_{\mathrm{p}}-\mathbf{q}}{\left\|\varepsilon_{\mathrm{p}}-\mathbf{q}\right\|}, \quad \mathbf{n}=\frac{\dot{\boldsymbol{\varepsilon}}_{\mathrm{p}}}{\left\|\dot{\varepsilon}_{\mathrm{p}}\right\|} .
$$

Let us suppose that uniaxial plastic strain is cycled between $\varepsilon_{\mathrm{p}}^{\min }$ and $\varepsilon_{\mathrm{p}}^{\max }$ under the condition of $\varepsilon_{\mathrm{p}}^{\min }<0<\varepsilon_{\mathrm{p}}^{\max }$. It is then shown that $q-\rho=\varepsilon_{\mathrm{p}}^{\min }$ and $q+\rho=\varepsilon_{\mathrm{p}}^{\max }$; consequently, $\rho=\left(\varepsilon_{\mathrm{p}}^{\max }-\varepsilon_{\mathrm{p}}^{\min }\right) / 2 \equiv \Delta \varepsilon_{\mathrm{p}} / 2$ and $q=\left(\varepsilon_{\mathrm{p}}^{\max }+\varepsilon_{\mathrm{p}}^{\min }\right) / 2 \equiv \varepsilon_{\text {pmean }}$. Thus, $\rho$ is equal to the amplitude of plastic strain, $\Delta \varepsilon_{\mathrm{p}} / 2$. Bearing this in mind, the saturation value $r_{\text {sat }}$ in Eq. (4) was proposed to be a function of $\rho$ (Lemaitre and Chaboche, 1990):

$$
\dot{r}=h_{r}\left[r_{\text {sat }}(\rho)-r\right] \dot{p}, r_{0}=r(0)
$$

The material function $r_{\text {sat }}(\rho)$ can be determined so as to represent the strain-range dependence of cyclic hardening observed in uniaxial cyclic tests. Here, it is noted that $\varepsilon_{\text {pmean }}$ usually has much smaller effect than $\Delta \varepsilon_{\mathrm{p}} / 2$ on cyclic hardening, as observed by Ellyin (1985) and Mizuno et al. (2000). ${ }^{1}$

It is, however, necessary to note the case in which uniaxial plastic strain is cycled between $\varepsilon_{\mathrm{p}}^{\min }$ and $\varepsilon_{\mathrm{p}}^{\max }$ after prestraining to $\varepsilon_{\mathrm{p}}^{\max }$ under the condition of $0<\varepsilon_{\mathrm{p}}^{\min }<\varepsilon_{\mathrm{p}}^{\max }$. In this case, it is shown that $q-\rho=0$ and $q+\rho=\varepsilon_{\mathrm{p}}^{\max }$; consequently, $\rho=\varepsilon_{\mathrm{p}}^{\max } / 2>\Delta \varepsilon_{\mathrm{p}} / 2$ and $q=\varepsilon_{\mathrm{p}}^{\max } / 2 \neq \varepsilon_{\text {pmean }}$. Hence, because $\rho$ is larger than the amplitude of plastic strain, Eq. (9) overpredicts cyclic hardening (Ohno, 1982).

\subsection{Nonhardening strain region}

Ohno (1982) postulated that isotropic hardening does not occur when plastic strain varies within a plastic strain region after a load reversal. Interest in this plastic strain region, referred to as the nonhardening strain region, was motivated by considering that dislocations piled up at obstacles may be remobilized under reverse loading, and thus a certain amount of plastic strain may proceed without a marked increase in dislocation density after a load reversal (Ohno and Kachi, 1986). It was assumed that the nonhardening region expands and translates when there is plastic strain on its surface, as schematically illustrated in Fig. 3. Then, as the nonhardening region expands, the development of cyclic hardening in one cycle reduces, and eventually, cyclic hardening is saturated.

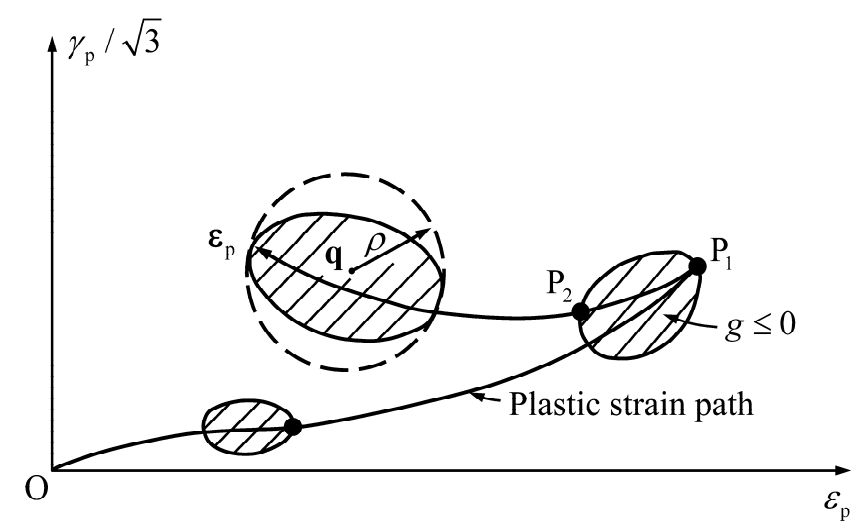

Fig. 3 Evolution of nonhardening region $g \leq 0$ in the space of axial plastic strain $\varepsilon_{\mathrm{p}}$ and shear plastic strain $\gamma_{\mathrm{p}}$; the region, which is approximated as a hypersphere of center $\mathbf{q}$ and radius $\rho$, does not evolve when plastic strain varies from $\mathrm{P}_{1}$ to $\mathrm{P}_{2}$ within the region (Ohno, 1982).

\footnotetext{
${ }^{1}$ If $\varepsilon_{\text {pmean }}$ is somewhat larger than $\Delta \varepsilon_{\mathrm{p}} / 2, \varepsilon_{\text {pmean }}$ may have some influence on the cyclic hardening (Ohno et al., 1998; Yoshida et al., 2002).
} 
The nonhardening region was expressed using an extension of the plastic strain memory surface $g=0$ described in Section 3.2. The extension was made to allow the translation and expansion of the nonhardening region $g \leq 0$ :

$$
\begin{aligned}
& g=\frac{2}{3}\left\|\varepsilon_{\mathrm{p}}-\mathbf{q}\right\|^{2}-\rho^{2}, \\
& \dot{\mathbf{q}}=(1-\mathrm{c}) \Gamma \frac{\boldsymbol{\varepsilon}_{\mathrm{p}}-\mathbf{q}}{\rho} \dot{p}, \quad \dot{\rho}=c \Gamma \dot{p},
\end{aligned}
$$

where $c$ is a material parameter, and $\Gamma$ is defined using $\mathbf{n}^{*}=\left(\partial g / \partial \boldsymbol{\varepsilon}_{\mathrm{p}}\right) /\left\|\partial g / \partial \boldsymbol{\varepsilon}_{\mathrm{p}}\right\|$ as

$$
\Gamma= \begin{cases}\frac{2\left(\boldsymbol{\varepsilon}_{\mathrm{p}}-\mathbf{q}\right): \dot{\boldsymbol{\varepsilon}}_{\mathrm{p}}}{3 \rho \dot{p}}, & \text { if } g=0 \text { and } \mathbf{n}^{*}: \dot{\boldsymbol{\varepsilon}}_{\mathrm{p}}>0, \\ 0, & \text { if } g<0 \text { or } \mathbf{n}^{*}: \dot{\boldsymbol{\varepsilon}}_{\mathrm{p}} \leq 0\end{cases}
$$

Equation (11) reduces to Eq. (7) if $c=1 / 2$.

By taking $\rho$ as a measure of isotropic hardening, the yield function was proposed as

$$
f=\frac{3}{2}\left\|\sigma^{\prime}-\alpha^{\prime}\right\|^{2}-r(\rho)^{2}
$$

Then, because $\dot{r}=(d r / d \rho) \dot{\rho}$, the yield surface does not change size when $\varepsilon_{\mathrm{p}}$ varies within the nonhardening region $g \leq 0$. It was further assumed that kinematic hardening is enhanced to compensate the absence of isotropic hardening within the nonhardening region $g \leq 0$ :

$$
\dot{\alpha}^{\prime}=\frac{2}{3}\left[h_{\alpha}+(1-\Gamma) \frac{d r(\rho)}{d \rho}\right] \dot{\varepsilon}_{\mathrm{p}}-\zeta_{\alpha} \frac{\alpha^{\prime}}{\left\|\alpha^{\prime}\right\|} \dot{p},
$$

where $h_{\alpha}$ and $\zeta_{\alpha}$ are material parameters, and the last term on the right hand side expresses a memory erasure effect on $\alpha^{\prime}$ based on the Armstrong-Frederick (1966) model.

\subsection{Two-surface model with nonhardening strain region}

The two-surface model assumes that a yield surface $f=0$ translates/expands within a bounding surface $F=0$ that is allowed to translate/expand (Dafalias and Popov, 1975, 1976; Krieg, 1975). ${ }^{2}$ In this model, the expansion of the bounding surface $F=0$ is responsible for the development of cyclic hardening, whereas the translation of the yield surface $f=0$ expresses the transient hardening observed just after yielding.

Using the two-surface model, Ohno and Kachi (1986) refined the material model described in Section 3.3; the nonhardening strain region $g \leq 0$ expressed as Eqs. (10) and (11) was applied to the expansion and translation of the bounding surface so that

$$
\begin{aligned}
& F=\frac{3}{2}\left\|\boldsymbol{\sigma}^{\prime}-\boldsymbol{\beta}^{\prime}\right\|^{2}-R(\rho)^{2}, \\
& \dot{\boldsymbol{\beta}}^{\prime}=\frac{2}{3}\left[h_{\beta}+(1-\Gamma) \frac{d R(\rho)}{d \rho}\right] \dot{\boldsymbol{\varepsilon}}_{\mathrm{p}}-\zeta_{\beta} \boldsymbol{\beta}^{\prime} \dot{p},
\end{aligned}
$$

where $\beta^{\prime}$ and $R$ respectively denote the center and radius of the bounding surface $F=0$ in the deviatoric stress space, $h_{\beta}$ and $\zeta_{\beta}$ are material parameters, and the evolution of $\rho$ and the definition of $\Gamma$ are given as Eqs. (11) and (12), respectively. Equation (16) reduces to the Armstrong-Frederick (1966) model in the absence of $d R(\rho) / d \rho$. It is emphasized that, because $\dot{R}=(d R / d \rho) \dot{\rho}$, the bounding surface $F=0$ does not expand when plastic strain varies within the nohardening region $g \leq 0$.

\footnotetext{
2 The two-surface model stems from the multi-surface model of Mróz (1967).
} 


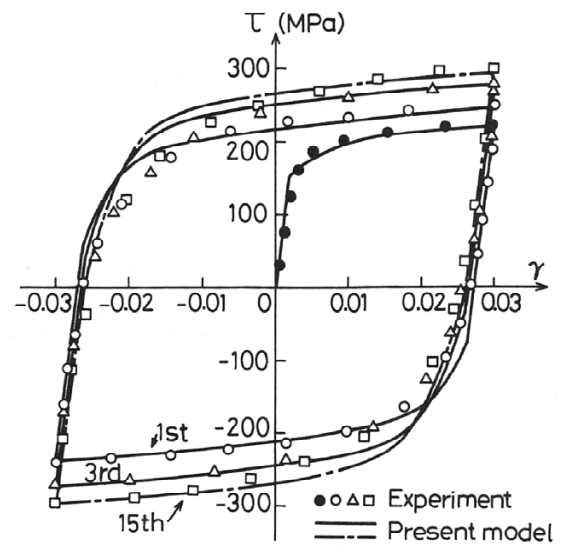

(a)

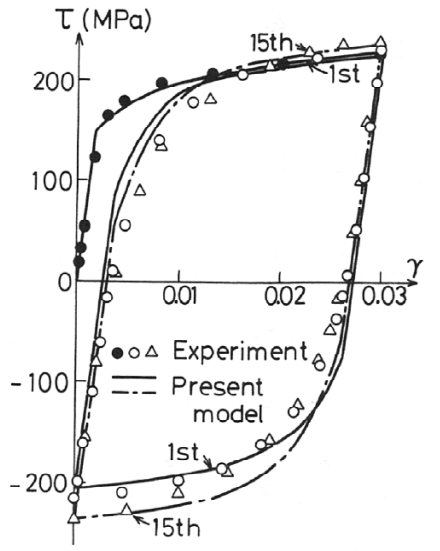

(b)

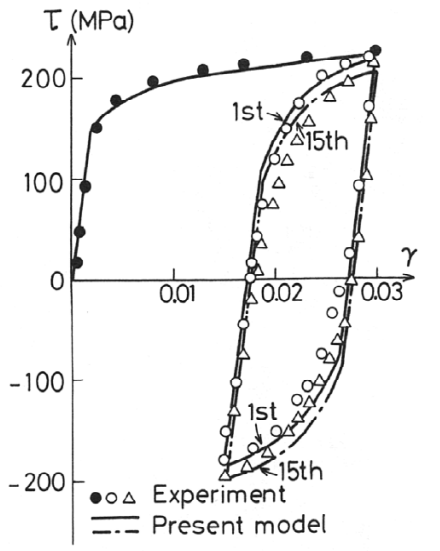

(c)

Fig. 4 Shear stress-strain hysteresis loops of 304 stainless steel subjected to cyclic shear loading with constant cyclic range of shear strain; (a) [-0.03, 0.03], (b) [0, 0.03], and (c) [0.015, 0.03] (Ohno and Kachi, 1986).

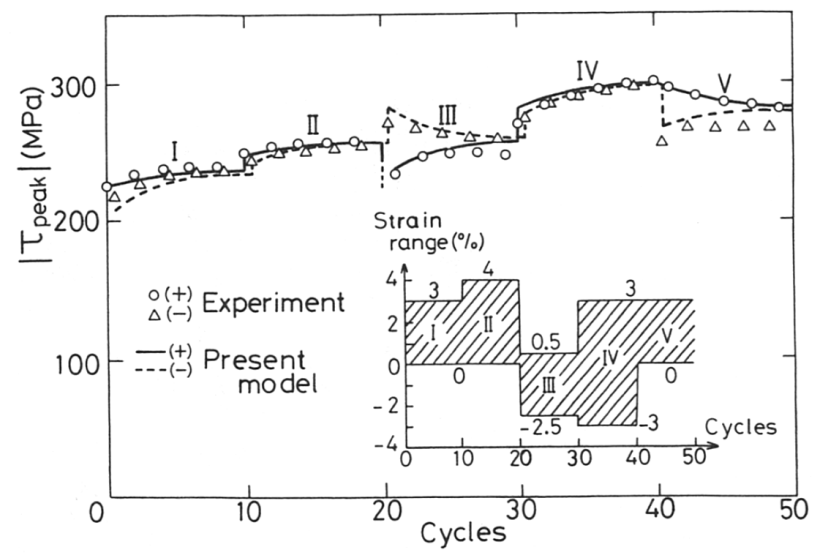

Fig. 5 Variation in peak shear stress $\tau_{\text {peak }}$ of 304 stainless steel subjected to cyclic shear loading with stepwise varying cyclic range of shear strain (Ohno and Kachi, 1986).

To verify the material model described above, Ohno and Kachi (1986) simulated the cyclic plastic behavior of 316L and 304 stainless steels reported by Chaboche et al. (1979) and Ohno (1982). Examples of the comparisons thus obtained are shown in Figs. 4 and 5, where $\tau$ and $\gamma$ indicate shear stress and shear strain, respectively. As seen from the figures, the material model reproduced well the experimental results in both cases of constant and varying strain ranges including the example shown in Fig. 4(c). In this example, shear strain was cycled between $\gamma^{\min }(=0.015)$ and $\gamma^{\max }(=0.03)$ that satisfy the condition $0<\gamma^{\min }<\gamma^{\max }$. It is noted that the plastic strain memory surface based on Eqs. (6) and (7) overpredicts cyclic hardening in such an example, as commented in the last paragraph of Section 3.2.

\subsection{Related studies}

Chaboche et al. (1979) observed a little recovery of cyclic hardening after a stepwise decrease in $\Delta \varepsilon$ (Fig. 1(b)). To simulate this recovery, the plastic strain memory surface extended as Eqs. (10) and (11) was further extended by adding a memory erasure term (Nouailhas et al., 1985). This extended memory surface has been recently used for the material modeling of OFHC copper subjected to cyclic loading (Zhang and Jiang, 2008) and for the multi-mechanism material modeling of cyclic plasticity (Taleb et al., 2014; Saï et al., 2014). The strain-range-dependent cyclic hardening simulated in this way is depicted for OFHC copper in Fig. 2.

The nonhardening strain region based on Eqs. (10) and (11) was used for the nonisothermal cyclic hardening behavior of 304 stainless steel (Ohno et al., 1989). A similar region was considered to simulate transient creep after a stress reversal (Murakami and Ohno, 1982). A different approach for strain-range-dependent cyclic hardening was proposed by Kang et al. (2003). In their approach, the Ohno-Wang (1993) model was used to assume that isotropic, as 
well as kinematic, hardening consists of several parts, and also that each part of isotropic hardening evolves only when the corresponding part of kinematic hardening is in the critical state of dynamic recovery.

\section{Workhardening stagnation}

\subsection{Experimental observations}

Hasegawa et al. (1975) experimentally investigated the deformation behavior of a polycrystalline aluminum subjected to compression following tension at several temperatures ranging from room temperature to $450{ }^{\circ} \mathrm{C}$. They thus found that the workhardening rate became negligibly smaller in an early stage under the reverse loading than just before the unloading, as illustrated in Fig. 6 with the experimental data of a mild steel. The decrease in the workhardening rate under reverse loading, which is called workhardening stagnation, has been observed to occur in other metals subjected to large prestrains (e.g., Yakou et al., 1985; Christodoulou et al., 1986; Hu et al., 1992; Yoshida et al., 2002; Kuwabara, 2007). The following features have thus been revealed. Workhardening stagnation follows transient hardening after a load reversal, and leads to permanent softening; i.e., plastic flow stress under reverse loading continues to deviate from that predicted by the isotropic hardening model (Fig. 6). Workhardening stagnation becomes more noticeable with an increase in prestrain (Fig. 7). The TEM observations of dislocation structures made by Hasegawa et al. (1975), Christodoulou et al. (1986), and Rauch and Schmitt (1989) imply that workhardening stagnation is caused by the dissolution and reconstruction of dislocation cell walls under reverse loading.

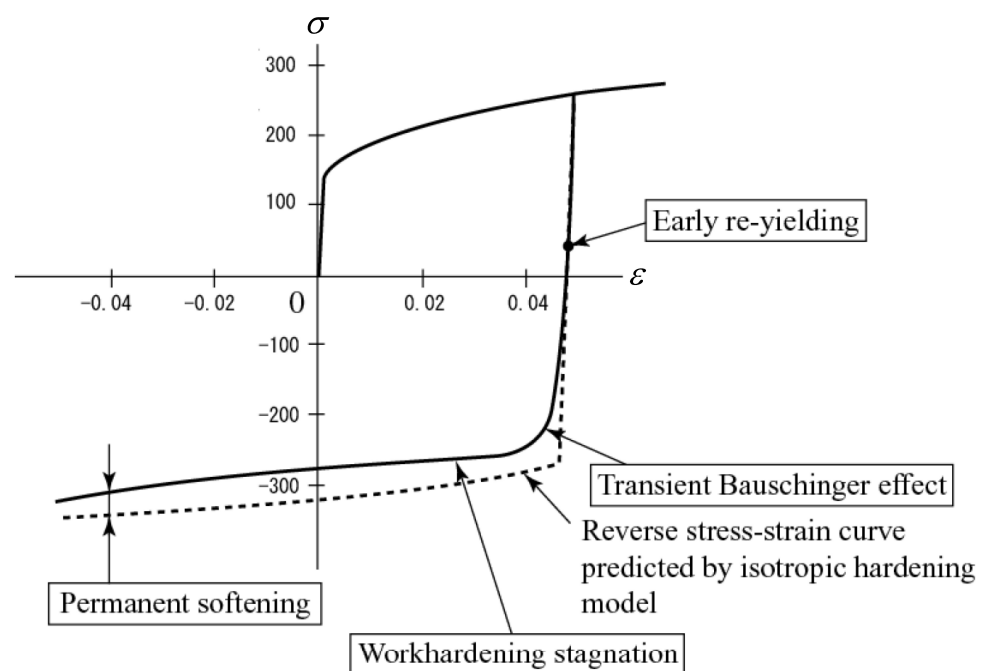

Fig. 6 Transient Bauschinger effect, workhardening stagnation, and permanent softening of a mild steel (SPCC) under reverse loading (stress in MPa) (Yoshida and Uemori, 2003; Yoshida, 2010).

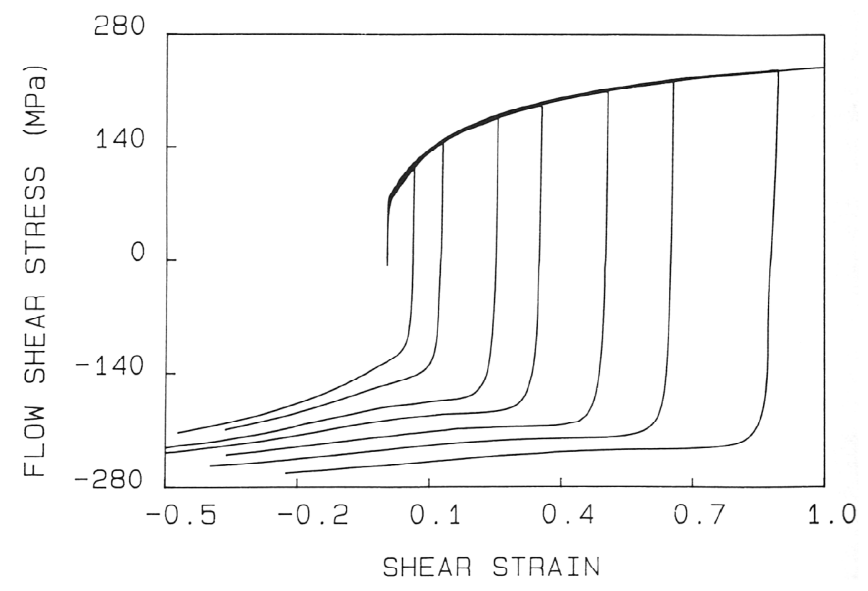

Fig. 7 Shear stress-strain curves of a mild steel under reversed shear loading following several shear prestrains of $6 \%$, $13 \%, 25 \%, 35 \%, 50 \%, 65 \%$ and $88 \%$ (Hu et al., 1992). 


\subsection{Two-surface model with nonhardening stress region (Yoshida-Uemori model)}

Yoshida and Uemori (2002) proposed a material model of large-strain cyclic plasticity to analyze springback accurately. This model, which is called the Yoshida-Uemori or Y-U model, was constructed to represent the transient hardening, workhardening stagnation, and permanent softening illustrated in Fig. 6. Also taken into account in the Y-U model are the yield function form for texture anisotropy and the apparent decrease in Young's modulus due to plastic deformation. This decrease in Young's modulus, which is referred to as Young's modulus degradation hereafter, is likely to occur to a certain degree even at such a small strain as $2.0 \%$ (Morestin and Boivin, 1995; Yoshida et al., 2002; Andar et al., 2010; Sun and Wagoner, 2011) in contrast to that due to material damage reported by Lemaitre (1985).

The Y-U model is based on the two-surface model, in which a yield surface $f=0$ translates/expands within a bounding surface $F=0$ that translates/expands (Dafalias and Popov, 1975, 1976; Krieg, 1976). The Y-U model is moreover based on the postulation that isotropic hardening does not evolve for a while after a load reversal (Ohno, 1982). Noting that the expansion of the bounding surface is mainly responsible for the evolution of isotropic hardening, Yoshida and Uemori (2002) represented workhardening stagnation and permanent softening by assuming that the bounding surface $F=0$ does not change its size $R$ when the deviatoric part $\beta^{\prime}$ of its center $\beta$ is placed within a stress region $g_{\sigma} \leq 0$ :

$$
\begin{aligned}
& F=\phi(\boldsymbol{\sigma}-\boldsymbol{\beta})-R, \\
& \dot{R}= \begin{cases}h_{R}\left(R_{\mathrm{sat}}-R\right) \dot{p}, & \text { if } g_{\sigma}=0 \text { and } \mathbf{n}_{\sigma}^{*}:{ }^{\circ} \boldsymbol{\beta}^{\prime}>0, \\
0, & \text { if } g_{\sigma}<0 \text { or } \mathbf{n}_{\sigma}^{*}:{ }^{\circ} \boldsymbol{\beta}^{\prime} \leq 0 .\end{cases}
\end{aligned}
$$

Here, $\phi$ is a homogeneous function of degree one, $h_{R}$ and $R_{\text {sat }}$ are material parameters, $\dot{p}$ denotes the accumulated plastic strain rate at large strains, $\mathbf{n}_{\sigma}^{*}$ is defined as $\mathbf{n}_{\sigma}^{*}=\left(\partial g_{\sigma} / \partial \boldsymbol{\beta}^{\prime}\right) /\left\|\partial g_{\sigma} / \partial \boldsymbol{\beta}^{\prime}\right\|,{ }^{\circ} \boldsymbol{\beta}^{\prime}$ indicates the objective rate of $\beta^{\prime}$ and is assumed to obey the Armstrong-Frederick (1966) model, and

$$
\begin{aligned}
& g_{\sigma}=\frac{3}{2}\left\|\boldsymbol{\beta}^{\prime}-\mathbf{q}_{\sigma}^{\prime}\right\|^{2}-\rho_{\sigma}^{2}, \\
& \dot{\rho}_{\sigma}= \begin{cases}\frac{3 h_{\rho}\left(\boldsymbol{\beta}^{\prime}-\mathbf{q}_{\sigma}^{\prime}\right):{ }^{\circ} \boldsymbol{\beta}^{\prime}}{2 \rho_{\sigma}}, & \text { if } \dot{R}>0, \\
0, & \text { if } \dot{R}=0,\end{cases} \\
& { }^{\circ} \mathbf{q}_{\sigma}^{\prime}=\mu\left(\boldsymbol{\beta}^{\prime}-\mathbf{q}_{\sigma}^{\prime}\right), \mu=\frac{3\left(\boldsymbol{\beta}^{\prime}-\mathbf{q}_{\sigma}^{\prime}\right):{ }^{\circ} \boldsymbol{\beta}^{\prime}}{2 \rho_{\sigma}^{2}}-\frac{\dot{\rho}_{\sigma}}{\rho_{\sigma}},
\end{aligned}
$$

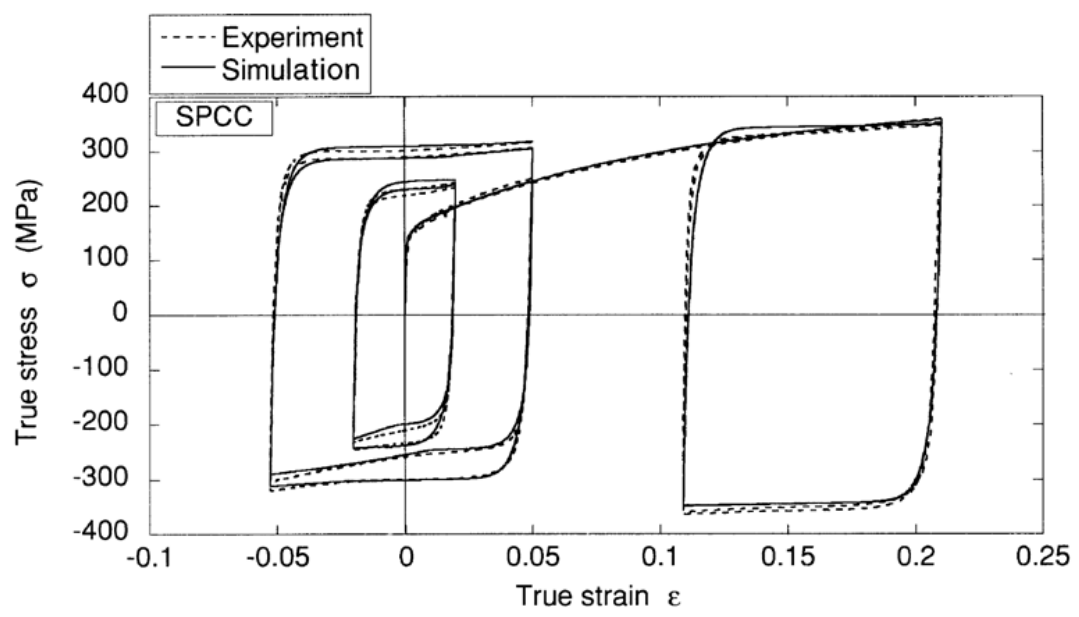

Fig. 8 Uniaxial stress-strain hysteresis loops of a mild steel (SPCC); experimental data, and simulation results obtained using the Yoshida-Uemori model (Yoshida and Uemori, 2002). 
where $\mathbf{q}_{\sigma}^{\prime}$ and $\rho_{\sigma}$ respectively denote the center and radius of the stress region $g_{\sigma} \leq 0$, and $h_{\rho}$ is a material parameter. In the presence of texture anisotropy, the function $\phi$ takes an anisotropic form such as Hill's function (Hill, 1990) or Barlat's YLD2000-2d function (Barlat et al., 2003). The stress region $g_{\sigma} \leq 0$ has been called the non-IH (isotropic hardening) region after the nonhardening strain region described in Section 3.3.

Figure 8 shows the stress-strain hysteresis loops obtained by applying the Y-U model to a large-strain cyclic test, in which a mild steel sheet noticeably exhibited workhardening stagnation and permanent softening (Yoshida and Uemori, 2002).

\subsection{Other material models}

Takahashi et al. (1998) proposed a polycrystal plasticity model for simulating workhardening stagnation. Their model was based on the assumption that workhardening does not evolve within a slip strain range, called the backlash range, in each slip system (Takahashi and Shiono, 1991). This assumption is essentially the same as that of the nonhardening strain region postulated by Ohno (1982). Recently, the nonhardening strain region at large strains has

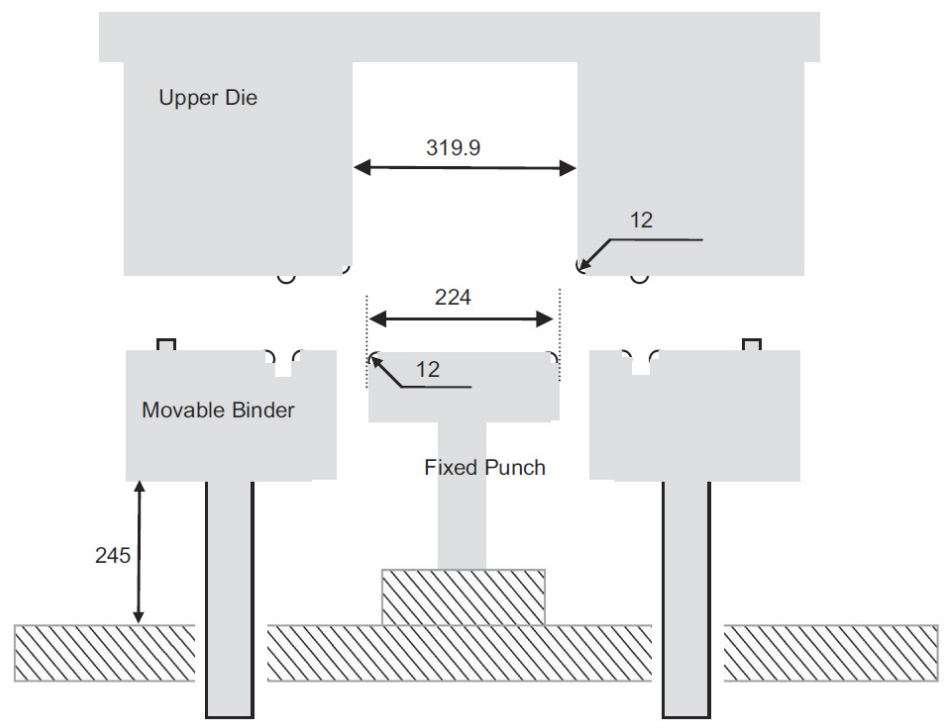

Fig. 9 Schematic illustration of the Numisheet 2005 channel draw process (dimensions are in mm) (Green, 2005; Ghaei et al., 2010).

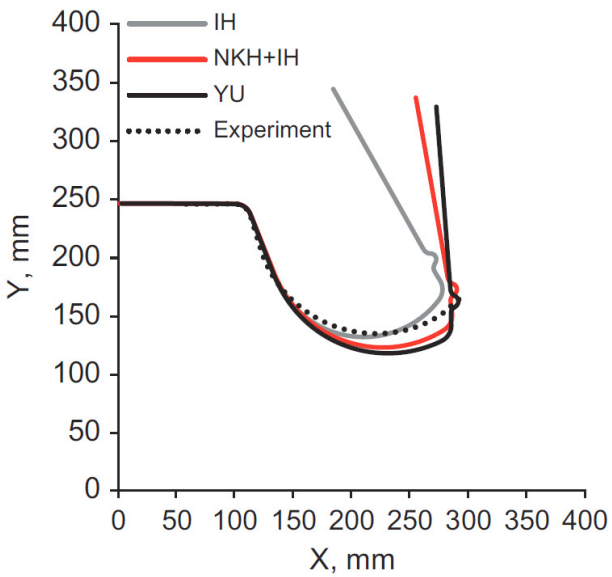

(a)

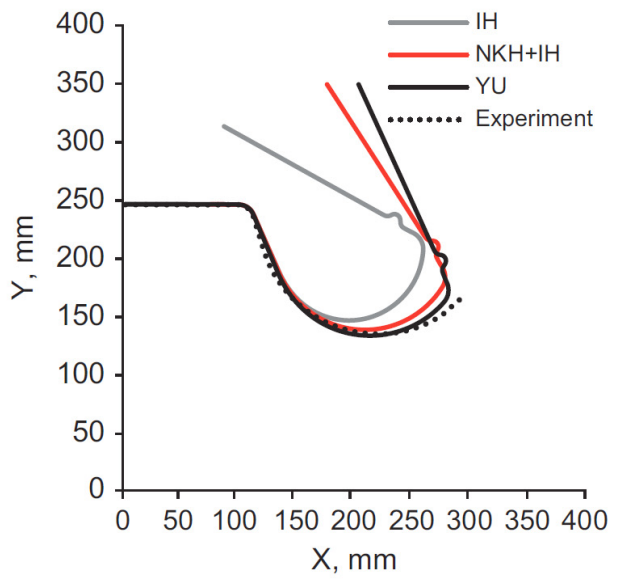

(b)

Fig. 10 Springback profile of a dual-phase (DP600) steel sheet in the Numisheet 2005 channel draw process, illustrated in Fig. 9, at $75 \%$ drawbed penetration; comparison of experimental profile with those predicted using the isotropic hardening model $(\mathrm{IH})$, combined isotropic-nonlinear kinematic hardening model $(\mathrm{NKH}+\mathrm{IH})$, and Yoshida-Uemori model (Y-U) in finite element analysis (a) without and (b) with Young's modulus degradation (Ghaei et al., 2010). 
been used to simulate workhardening stagnation in the framework of the subloading surface model (Hashiguchi et al., 2012; Hashiguchi, 2014). The nonhardening strain region has also been used to replace the nonhardening stress region in the Y-U model so as to improve the model (Jia and Kuwamura, 2014; Jia, 2014).

$\mathrm{Hu}$ et al. (1992) and Haddadi et al. (2006) developed physics-based continuum models of workhardening stagnation, in which internal variables related with the dissolution and reconstruction of dislocation cell walls were introduced in uniaxial and multiaxial forms, respectively.

\subsection{Applications to springback analysis}

Yoshida and Uemori (2003) demonstrated that the Y-U model can predict springback accurately in comparison with other models. The Y-U model has thus been officially available in LS-DYNA and PAM-STAMP since 2007, where a dynamic explicit integration scheme was used to implement the model. A semi-implicit integration scheme was then developed to implement the Y-U model in finite element programs, and the Y-U model was shown to predict well springback in the channel draw process illustrated in Fig. 9, as depicted in Fig. 10 (Ghaei and Green, 2010; Ghaei et al., 2010). The Y-U model was further applied to simulating bending and springback of a stainless-steel clad aluminum sheet (Yilamu et al., 2010). Five material models including the Y-U model were examined to illustrate that the Young's modulus degradation due to plastic deformation, as well as the yield function form that takes account of texture anisotropy, is important for accurately simulating springback (Eggertsen and Mattiasson, 2009, 2010). ${ }^{3,4}$ The physics-based continuum model of workhardening stagnation developed by Haddadi et al. (2006) was applied to springback analysis by Oliveira et al. (2007). Recent advances in springback analysis were reviewed in detail by Wagoner et al. (2013).

\section{Summary}

The material models of cyclic plasticity in which memory surfaces are used to extend isotropic hardening for simulating strain-range-dependent cyclic hardening and workhardening stagnation were reviewed. This class of material modeling dates back to the study of Chaboche et al. (1979), in which a plastic strain memory surface was introduced to memorize the maximum and minimum plastic strains for taking into account strain-range-dependent cyclic hardening in a material model. Ohno (1982) then postulated that isotropic hardening does not evolve within a plastic strain region after a load reversal, and represented this strain region, referred to as the nonhardening strain region, using a generalization of the plastic strain memory surface. He thus developed a material model for simulating strain-range-dependent cyclic hardening. Ohno and Kachi (1986) refined this material model by incorporating the nonhardening strain region in the two-surface model developed by Dafalias and Popov $(1975,1976)$ and Krieg (1975). Afterward, Yoshida and Uemori (2002) introduced a nonhardening region in the stress space at large strains, called the non-IH (isotropic hardening) region, to simulate workhardening stagnation and permanent softening; they also used the two-surface model. The Yoshida-Uemori model was then demonstrated to be able to accurately simulate springback in sheet metal forming (Yoshida and Uemori, 2003), and has thus been formally available in LS-DYNA and PAM-STAMP since 2007. It is noted that the Young's modulus degradation due to plastic deformation and the yield function form for texture anisotropy are also taken into account in the Yoshida-Uemori model for accurate springback simulation. Advances in springback analysis were reviewed by Wagoner et al. (2013). Recently, the nonhardening stress region in the Yoshida-Uemori model has been replaced with the nonhardening strain region to improve the model (Jia and Kuwamura, 2014; Jia, 2014).

\section{Acknowledgments}

The author deeply appreciates the invitation to write a review paper for Mechanical Engineering Reviews. The author is, moreover, sincerely grateful to Professor Fusahito Yoshida, Hiroshima University, and Professor Toshihiko Kuwabara, Tokyo University of Agriculture and Technology, for helpful communications in writing this paper.

\footnotetext{
3 The Young's modulus degradation due to plastic deformation is usually determined by performing uniaxial loadingunloading tests. It was, however, revealed that this degradation depends on the stress ratio of biaxial loading-unloading (Andar et al., 2010).

4 Tension-compression asymmetry or strength-differential effect also affects springback, and hence was accurately measured by developing an apparatus using comb-type dies for in-plane stress reversal tests of sheet metals (Kuwabara et al., 2009).
} 


\section{References}

Andar, M.O., Kuwabara, T., Yonemura, S., Uenishi, A., Elastic-plastic and inelastic characteristics of high strength steel sheets under biaxial loading and unloading, ISIJ International, Vol.50, No.4 (2010), pp.613-619.

Armstrong, P.J., Frederick, C.O., A mathematical representation of the multiaxial Bauschinger effect, CEGB Report RD/B/N/731 (1966), Berkeley Nuclear Laboratories, UK.

Barlat, F., Brem, J.C., Yoon, J.W., Chung, K., Dick, R.E., Lege, D.J., Pourboghrat, F., Choi, S.H., Chu, E., Plane stress yield function for aluminum alloy sheets - part 1: theory, International Journal of Plasticity, Vol.19, No.9 (2003), pp.1297-1319.

Bruhns, O.T., Some remarks on the history of plasticity - Heinrich Hencky, a pioneer of the early years, Lecture Notes in Applied Mathematics and Mechanics, Vol.1 (2014a), pp.133-152.

Bruhns, O.T., The Prandtl-Reuss equations revisited, Zeitschrift für Angewandte Mathematik und Mechanik, Vol.94, No. 3 (2014b), pp.187-202.

Chaboche, J.L., Time-independent constitutive theories for cyclic plasticity, International Journal of Plasticity, Vol.2, No.2 (1986), pp.149-188.

Chaboche, J.L., Constitutive equations for cyclic plasticity and cyclic visicoplasticity, International Journal of Plasticity, Vol.5, No.3 (1989), pp.247-302.

Chaboche, J.L., A review of some plasticity and viscoplasticity constitutive theories, International Journal of Plasticity, Vol.24, No.10 (2008), pp.1642-1693.

Chaboche, J.L., Dang Van, K., Cordier, G., Modelization of the strain memory effect on the cyclic hardening of 316 stainless steel, Transactions of the 5th International Conference on Structural Mechanics in Reactor Technology, Vol.L (1979), Paper No. L11/3.

Christodoulou, N., Woo, O.T., MacEwen, S.R., Effect of stress reversals on the work hardening behavior of polycrystalline copper, Acta Metallurgica, Vol.34, No.8 (1986), pp.1553-1562.

Dafalias Y.F., Popov, E.P., A model of nonlinearly hardening materials for complex loading, Acta Mechanica, Vol.21, No.3 (1975), pp.173-192.

Dafalias Y.F., Popov, E.P., Plastic internal variables formalism of cyclic plasticity, Journal of Applied Mechanics Transactions of the ASME, Vol.43, No.4 (1976), pp.645-651.

Eggertsen, P.A., Mattiasson, K., On the modeling of the bending-unbending behaviour for accurate springback predictions, International Journal of Mechanical Sciences, Vol.51, No.7 (2009), pp.547-563.

Eggertsen, P.A., Mattiasson, K., On constitutive modeling for springback analysis, International Journal of Mechanical Sciences, Vol.52, No.6 (2010), pp.804-818.

Ellyin, F., Effect of tensile-mean-strain on plastic strain energy and cyclic response, Journal of Engineering Materials and Technology - Transactions of the ASME, Vol.107, No.2 (1985), pp.119-125.

Ghaei, A., Green, D.E., Numerical implementation of Yoshida-Uemori two-surface plasticity model using a fully implicit integration scheme, Computational Materials Science, Vol.48, No.1 (2010), pp.195-205.

Ghaei, A., Green, D.E., Taherizadeh, A., Semi-implicit numerical integration of Yoshida-Uemori two-surface plasticity model, International Journal of Mechanical Sciences, Vol.52, No.4 (2010), pp.531-540.

Green, D.E., Description of Numisheet 2005 benchmark \#3 stage-1: channel draw with 75\% drawbead penetration, Proceedings of Numisheet 2005, Vol.B (2005), pp.894-904, American Institute of Physics.

Haddadi, H., Bouvier, S., Banu, M., Maier, C., Teodosiu, C., Towards an accurate description of the anisotropic behaviour of sheet metals under large plastic deformations: modelling, numerical analysis and identification, International Journal of Plasticity, Vol.22, No.12 (2006), pp.2226-2271.

Hasegawa, T., Yakou, T., Karashima, S., Deformation behaviour and dislocation structures upon stress reversal in polycrystalline aluminium, Materials Science and Engineering, Vol.20, No.3 (1975), pp.267-276.

Hashiguchi, K., Elastoplasticity Theory, Second Edition (2014), p. 215, Springer.

Hashiguchi, K., Ueno, M., Ozaki, T., Elastoplastic model of metals with smooth elastic-plastic transition, Acta Mechanica, Vol.223, No.5 (2012), pp.985-1023.

Hill, R., Constitutive modelling of orthotropic plasticity in sheet metals, Journal of the Mechanics and Physics of Solids, Vol.38, No.3 (1990), pp.405-417. 
Hu, Z.Q., Rauch E.F., Teodosiu, C., Work-hardening behavior of mild steel under stress reversal at large strains, International Journal of Plasticity, Vol.8, No.7 (1992), pp.839-856.

Jia, L.J., Integration algorithm for a modified Yoshida-Uemori model to simulate cyclic plasticity in extremely large plastic strain ranges up to fracture, Computers \& Structures, Vol.145 (2014), pp.36-46.

Jia, L.J., Kuwamura, K., Prediction of cyclic behaviors of mild steel at large plastic strain using coupon test results, Journal of Structural Engineering, Vol.140, No.2 (2014), 04013056.

Jiang, Y.Y., Kurath, P., An investigation of cyclic transient behavior and implications on fatigue life estimates, Journal of Engineerng Materials and Technology - Transactions of the ASME, Vol.119, No.2 (1997), pp.161-170.

Jiang, Y.Y., Zhang, J.X., Benchmark experiments and characteristic cyclic plastic deformation, International Journal of Plasticity, Vol.24, No.9 (2008), pp.1481-1515.

Kang, G.Z., Ratchetting: recent progresses in phenomenon observation, constitutive modeling and application, International Journal of Fatigue, Vol.30, No.8 (2008), pp.1448-1472.

Kang, G.Z., Ohno, N., Nebu, A., Constitutive modeling of strain range dependent cyclic hardening, International Journal of Plasticity, Vol.19, No.10 (2003), pp.1801-1819.

Krieg, R.D., A practical two surface plasticity theory, Journal of Applied Mechanics - Transactions of the ASME, Vol.42, No.3 (1975), pp.641-646.

Kuwabara, T., Advances in experiments on metal sheets and tubes in support of constitutive modeling and forming simulations, International Journal of Plasticity, Vol.23, No.3 (2007), pp.385-419.

Kuwabara, T., Kumano, Y., Ziegelheim, J., Kurosaki, I., Tension-compression asymmetry of phosphor bronze for electronic parts and its effect on bending behavior, International Journal of Plasticity, Vol.25, No.9 (2009), pp. 1759-1776.

Lemaitre, J., A continuous damage mechanics model for ductile fracture, Journal of Engineering Materials and Technology - Transaction of the ASME, Vol.107, No.1 (1985), pp.83-89.

Lemaitre, J., Chaboche, J.L., Mechanics of Solid Materials (1990), p.161, Cambridge University Press.

Mayama, T., Sasaki, K., Kuroda, M., Quantitative evaluations of strain amplitude dependent organization of dislocation structures due to cyclic plasticity in austenitic stainless steel 316L, Acta Materialia, Vol.56, No.12 (2008), pp.2735-2743.

Mizuno, M., Mima, Y., Abdel-Karim, M., Ohno, N., Uniaxial ratchetting of 316FR steel at room temperature - Part I: experiments, Journal of Engineering Materials and Technology - Transactions of the ASME, Vol.122, No.1 (2000), pp.29-34.

Morestin, F., Boivin, M., On the necessity of taking into account the variation in the Young modulus with plastic strain in elastic-plastic software, Nuclear Engineering and Design, Vol.162, No.1 (1996), pp.107-116.

Mróz, Z., On the description of anisotropic workhardening, Journal of the Mechanics and Physics of Solids, Vol.15, No.3 (1967), pp.163-175.

Murakami, S., Ohno, N., A constitutive equation of creep based on the concept of a creep-hardening surface, International Journal of Solids and Structures, Vol.18, No.7 (1982), pp.597-609.

Nouailhas, D., Cailletaud, G., Policella, H., Marquis, D., Dufailly, J., Lieurade, H.P., Ribes, A., Bollinger, E., On the description of cyclic hardening and initial cold working, Engineering Fracture Mechanics, Vol.21, No.4 (1985), pp.887-895

Odqvist, F.K.G., Die verfestigung von flußeisenähnlichen körpern, ein beitrag zur plastizitätstheorie, Zeitschrift für Angewandte Mathematik und Mechanik, Vol.13, No.5 (1933), pp.360-363.

Ohno, N., A constitutive model of cyclic plasticity with a nonhardening strain region, Journal of Applied Mechanics Transactions of the ASME, Vol.49, No.4 (1982), pp.721-727.

Ohno, N., Recent topics in constitutive modeling of cyclic plasticity and viscoplasticity. Applied Mechanics Reviews, Vol.43, No.11 (1990), pp.283-295.

Ohno, N., Recent progress in constitutive modeling for ratchetting. Materials Science Research International, Vol.3, No.1 (1997), pp.1-9.

Ohno, N., Abdel-Karim, M., Kobayashi, M., Igari, T., Ratchetting characteristics of 316FR steel at high temperature, part I: strain-controlled ratchetting experiments and simulations, International Journal of Plasticity, Vol.14, No.4-5 (1998), pp.355-372.

Ohno, N., Kachi, Y., A constitutive model of cyclic plasticity for nonolinear hardening materials, Journal of Applied 
Mechanics - Transactions of the ASME, Vol.53, No.2 (1986), pp.395-403.

Ohno, N., Takahashi, Y., Kuwabara, K., Constitutive modeling of anisothermal cyclic plasticity of 304 stainless steel, Journal of Engineering Materials and Technology - Transactions of the ASME,, Vol.111, No.1 (1989), pp.106-114.

Ohno, N., Wang, J.D., Kinematic hardening rules with critical state of dynamic recovery, part I: formulation and basic features for ratchetting behavior, International Journal of Plasticity, Vol.9, No.3 (1993), pp.375-390.

Oliveira, M.C., Alves, J.L., Chaparro, B.M., Menezes, L.F., Study on the influence of work-hardening modeling in springback prediction, International Journal of Plasticity, Vol.23, No.3 (2007), pp.516-543.

Rauch, E.F., Schmitt, J.H., Dislocation substructures in mild steel deformed in simple shear, Materials Science and Engineering: A, Vol.113 (1989), pp.441-448.

Saï, K., Taleb, L., Guesmi, F., Cailletaud, G., Multi-mechanism modeling of proportional and non-proportional ratchetting of stainless steel 304, Acta Mechanica, Vol.225, No.11 (2014), pp.3265-3283.

Schmidt, R., Über den zusammenhang von spannungen und formänderungen im verfestigungsgebiet, Ingenieur-Archiv, Vol.3 (1932), pp.215-235.

Sun, L., Wagoner, R.H., Complex unloading behavior: nature of the deformation and its consistent constitutive representation, International Journal of Plasticity, Vol.27, No.7 (2011), pp.1126-1144.

Takahashi, H., Shiono, I., Backlash model for large deformation behavior of aluminum under torsional cyclic loading, International Journal of Plasticity, Vol.7, No.3 (1991), pp.199-217.

Takahashi, H., Fujiwara, K., Nakagawa, T., Multiple-slip work-hardening model in crystals with application to torsion-tension behaviors of aluminium tubes, International Journal of Plasticity, Vol.14, No.6 (1998), pp.489-509.

Taleb, L., Cailletaud, G., Saï, K., Experimental and numerical analysis about the cyclic behavior of the 304L and $316 \mathrm{~L}$ stainless steels at $350^{\circ} \mathrm{C}$, International Journal of Plasticity, Vol.61 (2014), pp.32-48.

Wagoner, R.H., Lim, H., Lee, M.G., Advances in springback, International Journal of Plasticity, Vol.45 (2013), pp.3-20.

Yakou, T., Hasegawa, T., Karashima, S., Stagnation of strain hardening during reversed straining of prestrained aluminium, copper and iron, Transaction of the Japan Institute of Metals, Vol.26, No.2 (1985), pp.88-93.

Yilamu, K., Hino, R., Hamasaki, H., Yoshida, F., Air bending and springback of stainless steel clad aluminum sheet, Journal of Material Processing Technology, Vol.210, No.2 (2010), pp.272-278.

Yoshida, F., Material models for accurate simulation of sheet metal forming and springback, Proceedings of the 10th International Conference on Numerical Methods in Industrial Forming Processes (NUMIFORM 2010) (2010), pp.71-80, American Institute of Physics.

Yoshida, F., Uemori, T., A model of large-strain cyclic plasticity describing the Bauschinger effect and workhardening stagnation, International Journal of Plasticity, Vol 18, No.5-6 (2002), pp.661-686.

Yoshida, F., Uemori, T., A model of large-strain cyclic plasticity and its application to springback simulation, International Journal of Mechanical Sciences, Vol.45, No.10 (2003), pp.1687-1702.

Yoshida, F., Uemori, T., Fujiwara, K., Elastic-plastic behavior of steel sheets under in-plane cyclic tension-compression at large strain, International Journal of Plasticity, Vol.18, No.5-6 (2002), pp.633-659.

Zhang, J.X., Jiang, Y.Y., Constitutive modeling of cyclic plasticity deformation of a pure polycrystalline copper, International Journal of Plasticity, Vol.24, No.10 (2008), pp.1890-1915. 